\title{
Planejamento Familiar em Mulheres de Alto Risco de Câncer de Mama
}

Family Planning in Women With High Risk for Breast Cancer

\author{
Maria Fernanda de Matos Malưf', Lincon Jô Mori ${ }^{2}$, Alfredo Carlos Simões Dornellas de Barros ${ }^{3}$
}

\section{Resumo}

Este estudo visa a promover o conhecimento sobre o impacto da confirmação de mutação nos genes BRCA1 e BRCA2 sobre o planejamento familiar nas pacientes de alto risco para câncer de mama, através da revisão da literatura internacional. A literatura médica é abundante e rica no que concerne aos aspectos genéticos associados ao câncer de mama, desde a identificação desses genes em 1994 e 1995, fornecendo informaçôes preciosas sobre o teste e sua implicação para a vida do portador, como a decisão sobre os tratamentos cirúrgicos profiláticos, porém sem abordar claramente a questão do planejamento familiar. Dessa forma, torna-se imprescindível que os estudos sobre o planejamento familiar sejam aprofundados para que se possa compreender o impacto dessa descoberta tão precocemente na vida pessoal da mulher.

Palavras-chave: Neoplasias da Mama; Gene BRCA1; Gene BRCA2; Mastectomia; Planejamento familiar; Gravidez

${ }^{1}$ Psicóloga, Mestre em Ciências e Especialista em Sexualidade Humana pela Faculdade de Medicina da Universidade de São Paulo. Departamento de Psiquiatria do Hospital das Clínicas da Universidade de São Paulo

${ }^{2}$ Mastologista, Mestre e Doutor em Ciências pela Faculdade de Medicina da Universidade de São Paulo. Departamento de Mastologia do Hospital das Clínicas da Universidade de São Paulo

${ }^{3}$ Docente pela Universidade Santo Amaro. Departamento de Saúde Materno Infantil

Endereço para correspondência: Maria Fernanda de Matos Maluf. Rua Itacolomi, nº 601, CJ. 66 - Higienópolis - CEP: 01243-020 - São Paulo (SP), Brasil. E-mails: fernandamaluf1@terra.com.br / maluf.fernanda@gmail.com 


\section{INTRODUÇÃO}

O câncer de mama é a neoplasia maligna que mais acomete o sexo feminino, sendo responsável por cerca de $20 \%$ óbitos por câncer entre as mulheres ${ }^{1}$.

Entre os casos de câncer de mama, aproximadamente $5 \%$ a $10 \%$ estão associados ao fator genético, causados por mutaçôes hereditárias nos genes BRCA1 e BRCA2. Mulheres portadoras dessas alterações têm um risco aumentado de $56 \%$ a $87 \%$ de desenvolver câncer de mama e de $10 \%$ a $60 \%$ de desenvolver câncer de ovário ${ }^{2,3,4,5}$.

Assim, estima-se que, dentre os 49.800 casos novos $(50,71 \%)$ de câncer de mama ${ }^{6}$, aproximadamente 2.490 a 4.980 são provenientes de alteraçôes nos genes BRCA1 e 2 .

Diversos estudos vêm sendo realizados com o intuito de compreender essas mutações, propondo-se, assim, às mulheres e homens afetados, tratamentos profiláticos para uma melhor qualidade de vida ${ }^{3,7,8}$. Dentre esses, os realizados por Smith et al. ${ }^{3}$, Bonadona et al. ${ }^{4}$, Speice et al. ${ }^{8}$ e Press et al. ${ }^{9}$ avaliaram as intençôes reprodutivas de adultos que receberam o diagnóstico genético de mutações do gene BRCA1, sendo o primeiro, o único, até o momento, a avaliar somente as intenções reprodutivas de indivíduos afetados.

Assim, é de suma importância a realização do teste genético para que o indivíduo tenha a certeza de que é $(67 \%)$ ou não portador dessas mutações, sendo assim capaz de realizar açōes preventivas (61\%) e planejar seu futuro reprodutivo, estimando, pois, o risco para seus filhos $(47 \%)^{10}$.

\section{MÉTODO}

Para esta revisão, realizou-se uma pesquisa nas bases de dados Medline, Pubmed, Lilacs e Cocrhane e na Revista Brasileira de Cancerologia, nos últimos dez anos, cruzando-se os unitermos: "BRCA vs planejamento familiar", "BRCA vs família", "BRCA vs mastectomia profilática", "BRCA vs gravidez".

Os idiomas utilizados nestas consultas foram o inglês e o português.
Não houve muitos retornos para os dois primeiros cruzamentos, tornando-se necessário ampliar-se o filtro para "mastectomia profilática" e "gravidez", assim se obteve maiores resultados.

Esses cruzamentos obtiveram os seguintes resultados (Tabela 1).

O cruzamento BRCA vs mastectomia profilática derivou-se dos demais devido à necessidade de aprofundar o tema estudado, já que esta é uma das formas de tratamento utilizada nos casos de pacientes com confirmação da mutação dos genes BRCA1 e 2 .

\section{RESULTADOS}

A literatura demonstra a implicação do alto risco para câncer de mama e a necessidade da profilaxia para tal como forma de prevenção.

Smith et al. ${ }^{3}$ entrevistaram 67 mulheres e 34 homens, entre os 18 e 45 anos de idade, com testes positivos $(n=25)$, negativos $(n=62)$ ou que não sabiam sobre alteraçōes $(n=14)$ para mutação no BRCA1. Estes foram avaliados no momento diagnóstico e depois em 4, 12 e 24 meses. Aproximadamente, 40\% (39/101 ou 38,6\%) referiam querer um novo filho nos três momentos das entrevistas de pós-teste. Dos 62 sujeitos restantes, 60\% (37/62), nestes mesmos períodos, estavam certos de que não queriam outro filho. Os outros $22,5 \%$ do subgrupo $(14 / 62)$ indicaram, durante o quarto mês de entrevista, que desejavam ter mais filhos, mas, então, informaram que estavam seguros de sua paternidade em um e dois anos após as entrevistas de pós-teste.

A redução das intenções de fertilidade entre mulheres portadoras e não-portadoras (e uma insignificante diferença entre homens portadores e não-portadores) também ocorreu nas entrevistas de um e dois anos. Entre as mulheres portadoras, o provável interesse em ter outro filho [odds ratio (OR) $0,12 \%$, intervalo de confiança (IC) $95 \% 0,01-1,23 ; p=0,0744]$ foi baixo em relação às não-portadoras. A proporção de sujeitos que referiram ter moderadamente ou muita certeza de que desejavam

Tabela 1. Resultados dos cruzamentos dos unitermos

\begin{tabular}{l|c|c|c|c}
\hline \multicolumn{1}{c|}{ CRUZAMENTOS } & \multicolumn{4}{c}{ BASE DE DADOS } \\
\hline & Pubmed & Medline & Lilacs/RBC & Cocrhane \\
\hline BRCA vs planejamento familiar & 2 & 15 & $0 / 0$ & 0 \\
\hline BRCA vs família & 229 & 1.160 & $4 / 0$ & 20 \\
\hline BRCA vs mastectomia profilática & 60 & 280 & $3 / 1$ & 22 \\
\hline BRCA vs gravidez & 27 & 227 & $0 / 1$ & 0 \\
\hline
\end{tabular}


outro filho foi de $59,4 \%, 47,5 \%$ e $41,6 \%$, em 4,12 e 24 meses, respectivamente.

Existe uma associação entre as mulheres que dão à luz mais cedo e a redução do desenvolvimento do câncer de mama na população geral, porém, para aquelas que possuem mutaçôes nos genes BRCA1 e 2, este efeito não é válido ${ }^{11-14}$.

Andrieu et al..$^{12}$ observaram aumento do risco de câncer de mama entre as portadoras da mutação do gene BRCA2 que tiveram gestaçôes em idade mais avançada comparadas àquelas com primeiro parto aos 20 anos (20-24, razão de risco $[R R]=2,33$ [95\% IC = 0,93 a 5,93]; 25-29, $\mathrm{RR}=2,68$ [95\% IC $=1,02$ a 7,07]). No entanto, entre as portadoras de mutação BRCA1, o risco de câncer de mama foi inversamente proporcional a idade da mulher no primeiro parto.

Jernström et al. ${ }^{13}$ realizaram estudo caso-controle para apontar e esclarecer os efeitos combinados do uso de anticoncepcionais orais e fatores genéticos em população com as mutaçóes BRCA1 e 2 testadas para câncer de mama desde o início.

Participaram do estudo 245 mulheres. O fato de nunca ter utilizado o contraceptivo oral ou o uso atual não foi associado ao câncer de mama. Os casos usaram mais contraceptivos orais antes dos 20 anos (relação ajustada de diferença (OR)) 2,10 (95\% CI 1,32-3,33), e antes de ter seu primeiro filho (ajustado OR 1,63 (95\% CI 1,02-2,62)). Quando estratificado por idade, o efeito do uso precoce de contraceptivos orais foi limitado a mulheres diagnosticadas antes dos 36 anos (OR) 1,53 (1,17-1,99 por ano de uso de contraceptivos orais antes dos 20 anos). Os riscos foram semelhantes para baixas-doses e altas-doses de contraceptivos orais. A probabilidade de ser portador de mutação BRCA1 e 2 era três vezes mais alta entre casos que começaram com o uso de contraceptivo oral prévio aos 20 anos, comparados com casos que começaram em idade de 20 anos ou mais, ou que nunca haviam usado contraceptivo oral. No entanto, a duração de uso de contraceptivo oral foi semelhante entre casos com e sem mutações BRCA1 e 2. Nenhuma associação foi vista com história familiar de primeiro grau de câncer de mama. Cada ano de uso de contraceptivo oral anterior aos 20 anos conferiu risco significativamente aumentado para início precoce do câncer de mama, enquanto não houve nenhum risco associado com uso após os 20 anos.

\section{DISCUSSÃO}

A descoberta do câncer de mama gera inúmeras mudanças na vida da mulher, tanto na esfera profissionalrelacional quanto pessoal. Dentro desta última, destacam-se as alterações no autoconceito, na imagem corporal e auto-imagem que podem refletir tanto no relacionamento conjugal como no sexual.

As alterações da imagem corporal e auto-imagem estão relacionadas e se completam. A mutilação do corpo feminino, oriunda da mastectomia radical, promove o luto pela perda do corpo real perfeito e sem mutilações para um corpo imperfeito e disforme em sua harmonia, fazendo com que a auto-imagem e $o$ autoconceito fiquem prejudicados ${ }^{1,14-17}$. Conseqüentemente, essas mudanças geram alterações na sexualidade, não somente ligadas às disfunções sexuais como também ao planejamento familiar.

Durante todas as etapas do tratamento, principalmente na fase diagnóstica, a mulher é acometida por inúmeras experiências internas, que abrangem desde o choque e negação da doença até uma fase em que ela aceita que tem câncer, procurando, pois, um tratamento ${ }^{1,14,17,18}$.

Esse processo vem acompanhado por um senso de alienação, decréscimo da auto-estima, desesperança, depressão, hostilidade e culpa aliados também aos sentimentos e pensamentos relacionados à antecipação da morte, que normalmente é posta a distância e até negada, apesar de ser um fato real e comum a todos os seres vivos, mas, em se tratando de câncer, passa a ser uma realidade. A relação câncer e morte fazem com o indivíduo repense sobre questões ligadas tanto à sua existência quanto a seus planos para o futuro, não só na esfera profissional mais também, principalmente, na familiar, em questōes relacionadas aos filhos, marido e ao planejamento familiar (ter ou não outros filhos) ${ }^{19}$.

Quando há o risco familiar para o câncer de mama, o indivíduo pode submeter-se ao teste genético para detectar a presença ou não da mutação nos genes BRCA1 e 2 , já que sua presença aumenta de $56 \%$ a $87 \%$ o risco de o portador desenvolver câncer de mama, e de $10 \%$ a $60 \%$ de desenvolver câncer de ovário ${ }^{2-5,20}$.

O teste genético costuma ser realizado por três motivos principais: obter segurança/certeza $(67 \%)$, ser capaz de realizar ações preventivas $(61 \%)$ e estimar o risco para os filhos $(47 \%)^{18}$. Frente à revelação do resultado, os portadores manifestam sentimentos angustiantes mais intensos (preocupação, raiva e/ou tristeza) do que previram, ao passo que os não afetados anteciparam exatamente suas reações emocionais ${ }^{4,21}$.

Havendo a confirmação da existência dessas mutações, ocorrem mudanças em relação aos planos futuros, como se pode observar nos resultados do estudo de Bonadona et al. ${ }^{4}$, no qual as pacientes com filhos (18/23) estavam preocupadas com o futuro dos mesmos, e seis de oito pacientes que desejavam ter filhos antes do resultado do teste genético reconsideraram os planos 
de ter uma família. As explicações dadas relacionavam-se ao adiar as decisões sobre a maternidade $(\mathrm{n}=5)$ e o não desejar ter mais filhos. A preocupação com a transmissão genética da mutação aos filhos foi manifesta por $17 \%$ das portadoras (4/17).

Ganz et al. ${ }^{20}$ verificaram que, dentre as $20 \%$ das pacientes que planejavam ou esperavam ter filhos antes do diagnóstico de câncer de mama, 11\% (61/577) desejaram a gravidez até o diagnóstico. Destas, 19\% não planejam uma gravidez por recomendação médica, $17 \%$ por preocupação com o risco e $29 \%$ devido a outras razões (relacionadas à idade ou à sua relação pessoal com a situação), porém $7 \%$ delas referiram que tentavam engravidar, $17 \%$ que desejavam engravidar, $12 \%$ tinham planos específicos ou de tratamentos para fertilidade encaminhados e $15 \%$ consideravam a hipótese de uma gravidez, mas estavam indecisas.

De modo geral, a descoberta da presença da mutação tem as seguintes vantagens e desvantagens para os pacientes (Tabela 2$)^{4}$.

\section{BRCA E CIRURGIAS PROFILÁTICAS}

Mulheres com alto risco de desenvolverem câncer de mama e de ovário podem submeter-se a cirurgias profiláticas como a mastectomia e/ou ooforectomia, objetivando a redução do risco para o desenvolvimento dessas neoplasias ${ }^{21}$.

Muitos estudos têm investigado a eficácia da mastectomia profilática bilateral para mulheres portadoras de mutações dos genes BRCA1 e $2^{21-23}$. Estima-se que o risco seja reduzido entre $85 \%$ a $100 \%$, sendo que a incidência de cirurgia profilática contralateral realizada na América do Norte é muito maior do que a, na Europa ${ }^{22}$.

Em um destes estudos, foram avaliadas 26 portadoras e 37 não-portadoras da mutação dos genes
BRCA1 e 2. Entre as portadoras, 14 submeteram-se à mastectomia profilática (média etária de 30 a 40 anos, com filhos) e oito destas também realizam a ooforectomia profilática, sendo que cinco a realizaram durante o mesmo tempo cirúrgico da mastectomia. As outras três evitaram a ooforectomia porque desejavam ter mais filhos ou acharam que a opção da mastectomia profilática já foi um sofrimento suficiente. As demais $(\mathrm{n}=12)$ optaram pelo rastreamento mamário, enquanto cinco delas submeteram-se à ooforectomia profilática.

Encontraram-se diferenças estatisticamente significantes relacionadas às mudanças na imagem corporal e no relacionamento íntimo $(\mathrm{p}<0,01 \mathrm{e} \mathrm{p}<0,05$, respectivamente) entre os três grupos estudados (portadoras que optaram pela mastectomia, portadoras que optaram pelo rastreamento constante e nãoportadoras), sendo os maiores problemas observados no grupo de portadoras submetidas à mastectomia ${ }^{2}$.

Cirurgias profiláticas como a mastectomia e a ooforectomia são de suma importância para a redução dos riscos de câncer, embora ambas sejam procedimentos mutilantes e irreversíveis que podem afetar a imagem corporal e a sexualidade ${ }^{10}$.

A mastectomia profilática, embora afete a imagem corporal e altere em $70 \%$ a relação sexual das pacientes portadoras de mutação nos genes BRCA1 e 2, tem benefício psicológico ao reduzir o temor de desenvolver câncer nessas mulheres ${ }^{11}$.

No âmbito da sexualidade, há prevalência geral entre $20 \%$ e $90 \%$ de disfunçôes sexuais, incluindo a diminuição da libido, impotência, decréscimo de interesse e dificuldades orgásmicas. Com relação ao câncer de mama, essa percentagem varia de $21 \%$ a 39\%, podendo essas disfunções sexuais estar associadas ao medo da mutilação e a rejeição sexual, sendo mais severas em mulheres que supervalorizam as mamas como

Tabela 2. Vantagens e desvantagens da descoberta da presença da mutação no gene BRCA

\begin{tabular}{l|c|l|c}
\multicolumn{2}{c|}{ VANTAGENS (n=23) } & \multicolumn{2}{c}{ DESVANTAGENS (n=23) } \\
\hline Tipo & n (\%) & \multicolumn{1}{c}{ Tipo } & n (\%) \\
\hline Simhuma & $7(30)$ & Nenhuma & $6(26)$ \\
\hline Cuidados médicos apropriados & $16(70)$ & Sim & $17(74)$ \\
\hline Melhorar, mudar o estilo de vida & $11(48)$ & Transmissão da mutação para seus filhos & $9(39)$ \\
\hline Somente saber & $4(17)$ & $\begin{array}{l}\text { Estresse, medo, preocupações } \\
\text { (reincidência, outro câncer) }\end{array}$ & $4(17)$ \\
\hline & $1(4)$ & Ser diferente de outros & $1(4)$ \\
\hline & & Não poder fazer planos para o futuro & $2(7)$ \\
\hline
\end{tabular}


fonte de atração, de auto-estima. A inabilidade em relaxar e desfrutar a relação pós-mastectomia também é um fator desencadeante de disfunções sexuais, devido às alteraçôes na imagem corporal ${ }^{15,17}$.

Hatcher et al. ${ }^{23}$ avaliaram o desconforto e o prazer sexual em 143 mulheres com alto risco de desenvolver câncer de mama, para as quais ofereceu-se a possibilidade de realizar a mastectomia bilateral profilática, sendo que estas poderiam aceitar ser operadas (grupo cirúrgico) ou não. Em relação ao primeiro, houve mudanças discretas durante o tempo dentro ou entre os grupos, com escores médios muito próximos ao máximo de 6 (escala de 0 a 6 , sendo 6 = não-desconforto), sendo 6 a média mantida pelo grupo cirúrgico, enquanto no grupo não-cirúrgico houve pequenas oscilações $(5$ e 5,5$)$ nãosignificantes, durante todo o estudo, em que os escores em 6 e 18 meses eram comparados com o escore de linha de base. Não houve alterações significantes relacionadas a decréscimo no prazer sexual em ambos os grupos (13,5 / 14 grupo cirúrgico; 12,5/15 e 13,5/ 13,5 grupo não-cirúrgico; escala de 0 a 18 , sendo 18 o escore de máximo prazer sexual).

Estudo recente mostrou que mulheres jovens submetidas à mastectomia profilática tendiam a estar menos satisfeitas com sua decisão do que mulheres mais velhas. Aproximadamente 1/3 referiu piora em sua vida sexual, independentemente se fizeram reconstrução. Aquelas que optaram pela reconstrução estavam mais satisfeitas com seus corpos, mas as mulheres de ambos os grupos sentiram a necessidade de manter seus corpos escondidos e evitar intimidade física. A angústia relacionada ao câncer era maior dentre aquelas com mutação no gene BRCA ou forte histórico familiar de câncer de mama do que naquelas sem esse histórico ${ }^{24}$.

\section{RELAÇÃO CONJUGAL E PLANEJAMENTO FAMILIAR}

Além das disfunções sexuais e das alterações sobre o exercício da sexualidade no que concerne à reprodução / planejamento familiar, o câncer de mama influi sobre todos à volta do indivíduo portador, como também a família que é a principal fonte de suporte social ${ }^{16,22}$.

Nas mulheres casadas ou com relacionamento estável, o marido desempenha um papel de grande importância através do suporte instrumental (prático) ou afetivo (emocional). Em muitos casos, o marido consegue e está acostumado a prover um suporte instrumental, porém a experiência relativa ao suporte emocional encontra-se diminuída. As mulheres com câncer de mama, às vezes, relatam que seus maridos são maravilhosos quando há algo concreto para eles fazerem como, por exemplo, buscar receitas, fazer anotações, organizar transporte e encontrar informaçôes na internet, mas têm dificuldade com as tarefas mais "sentimentais", tais como: escutar, segurar as mãos, tocar ${ }^{16,17}$.

Essas dificuldades "afetivas" demonstradas pelos maridos, muitas vezes, estão relacionadas às tensões por estes manifestadas e relatadas, que incluem solidão, incertezas, modificações nos padrōes de comunicação com a parceira, confusão sobre o que contar aos filhos, dificuldade relacionada ao aumentado de suas atividades no lar e o temor concernente ao impacto que a doença de suas esposas terá sobre toda a família. As mesmas questōes emocionais que comumente são relatadas pelas mulheres, também as são entre seus maridos, como as dificuldades de papel precipitado pelo câncer de mama que é sentida mais freqüentemente nas áreas da sexualidade e nas atividades de $\operatorname{lazer}^{17,22-24}$.

Em relação à estabilidade do casamento em decorrência do câncer de mama, aqueles que são constituídos por meio de uma sólida relação antes do surgimento do câncer costumam tornar-se mais sólidos, o que já não ocorre com os casamentos em que o ajustamento conjugal, no momento do diagnóstico, passava por dificuldades. A incidência de separações e divórcios devido ao câncer de mama não aumenta, embora possa criar tensão conjugal ${ }^{17,21}$.

Para Friedman e Kramen ${ }^{24}$, as mulheres em idade reprodutiva com mutaçôes BRCA1 e 2 devem confrontar decisôes sobre cirurgias de redução de risco (ooforectomia e mastectomia profilática), medidas anticoncepcionais e planejamento familiar. Estudos concernentes a esses temas freqüentemente têm conclusôes contraditórias. Os consultores genéticos e médicos aconselham os portadores de mutação BRCA1 e 2 sobre o efeito da gravidez no risco de câncer de mama, o papel da terapia de reposição hormonal, o uso de anticoncepcionais orais e ligação tubar e o uso de técnicas diagnósticas pré-natais.

$\mathrm{O}$ teste genético provém da oportunidade de, no caso de haver gravidez, optar-se pela interrupção da mesma se o feto estiver afetado. A pré-implantação do diagnóstico genético envolve o uso de fertilização de in vitro para criar vários embriōes. No terceiro dia, os embriôes têm de seis a dez células e de um a três serão removidos para análises, sendo que somente embriōes sadios serão reimplantados. Essa técnica vem sendo utilizada para pacientes portadoras de doenças como fibrose cística, doença de Huntington e distrofia muscular de Duchenne ${ }^{24}$.

O diagnóstico pré-natal para síndromes adultas com predisposição ao câncer é controverso, uma vez que as pessoas podem viver por 40 anos ou mais antes de desenvolverem câncer ou possuir a penetração incompleta da doença, alguns indivíduos gene positivo podem nunca 
ser afetados pelo câncer (assim como aqueles com a mutação BRCA). Outra objeção ao diagnóstico pré-natal e ao implante do diagnóstico pré-natal inclui o debate sobre o aborto e o status moral do embrião, assim como o processo de seleção em si, com alguns embriōes selecionados e outros descartados devido à composição genética ${ }^{24,25}$.

Profissionais de saúde, ao tratar ou consultar essas pacientes, devem discutir as opções disponíveis com elas e informá-las que, necessariamente, não existe um consenso de opinião sobre estas opções e sua eficácia relativa. A utilização de uma equipe multidisciplinar pode ser de suma importância, incorporando a perícia do aconselhamento genético: oncologistas cirúrgicos, médicos e ginecologistas, cirurgiōes plásticos e ginecologistas com experiência em técnicas de reprodução assistida. É também de suma relevância a inclusão de profissionais da área da saúde mental especialmente treinados nesse processo ${ }^{25}$.

\section{CONCLUSÃO}

O câncer de mama gera uma mudança completa na vida da mulher e de seus familiares. No que tange a si mesma, essa mudança é radical e munida de intenso sofrimento psíquico devido às alteraçôes da auto-imagem e imagem corporal (não-reconhecimento do corpo no pós-cirúrgico); pelo medo da aproximação da morte, de não poder fazer planos em longo prazo, de não ser ou sentir-se, ou perceber-se sexualmente atraente, de ser abandonada pelo cônjuge, filhos, parentes e amigos, de não poder ou não se permitir ter mais filhos por medo, devido à presença da mutação dos genes BRCA1 e 2, entre outros fatores. É um processo de reconstrução de si mesma (algumas vezes doloroso) para a retomada de seus próprios interesses e reconhecimento do próprio corpo, de seus desejos e necessidades.

No que tange ao planejamento familiar, a certeza de ser portadora da mutação dos genes BRCA1 e 2, e a possibilidade de transmissão para a prole faz com que a mulher viva o dilema de ter ou não outros filhos ou seu primogênito, e de vê-los crescer com o medo de quando o câncer de mama aparecerá, como noticiá-los de que são portadores e qual o momento adequá-lo para tal.

Os estudiosos são unânimes no concernente à relevância do impacto da presença da mutação dos genes BRCA1 e 2 sobre o planejamento familiar e o quão escasso é esse conhecimento, justificando, pois, seu estudo mais minucioso.

Compreender o dilema vivido por essas mulheres é de suma importância e merece a composição de uma equipe multidisciplinar composta também por profissionais da área de saúde mental que podem auxiliálas no processo de ressignificação e reestruturação de sua vida pessoal, incluindo-se o planejamento familiar, e de perceberem-se como mulher principalmente quando realizada a mastectomia profilática.

\section{REFERÊNCIAS}

1. Maluf MFM. Mastectomia radical e sexualidade feminina. São Paulo: Livraria Médica Paulista; 2006.

2. Lodder LN, Frets PG, Trisburg RW, Meijeboer-Heijboed EJ, Klijn JGC, Van Geel NA, et al. One year follow-up of women opting for presymptomatic test testing for the BRCA1/BRCA2: emotional impact of the test outcome at decision on risk management (surveillance or prophylactic surgery). Breast Cancer Res Treat. 2002;73(2):97-112.

3. Smith KR, Ellington L, Chan AY, Croyle RT, Botkin JR. Fertility intentions following testing for a BRCA 1 gene mutation. Cancer Epidemiology. 2004;13(5):733-40.

4. Bonadona V, Saltel P, Desseigne F, Mignotte H, Saurin JC, Wang $Q$, et al. Cancer patients who experienced diagnostic genetic testing for cancer susceptibility: reactions and behavior after the disclosure of a positive test result. Cancer Epidemiol Biomarkers Prev. 2002;11(1):97-104.

5. Antoniou A, Pharoah PD, Narod S, Risch HA, Eyfjord JE, Hopper JL, et al. Average risks of breast and ovarian cancer associated with BRCA 1 or BRCA 2 mutations detected in case series unselected for family: a combined analysis of 22 studies. Am J Hum Genet. 2003;72(5):1117-30. Epub 2003 Apr 3. Erratum in: Am J Hum Genet. 2003;73(3):709.

6. Instituto Nacional de Câncer. Estimativa 2008: incidência de câncer no Brasil [monografia na Internet]. Rio de Janeiro (Brasil): Instituto Nacional de Câncer; 2008 [citado em 2008 Jan 18]. Disponível em: http://www.inca.gov.br/ estimativa/2008/.

7. Ford D, Easton DF, Stratton M, Narod S, Goldgar D, Devilee $\mathrm{P}$, et al. Genetic heterogeneity and penetrance analysis of the BRCA 1 and BRCA 2 genes in breast cancer families. The breast cancer linkage consortium. Am J Hum Genet. 1998; 62(3):676-8.

8. Speice J, McDaniel SH, Rowley PT, Loader S. Family issues in a psychoeducation group for women with a BRCA mutation. Clin Genet. 2002;62(2):121-7.

9. Press NA, Yasui Y, Reynolds S, Durfy SJ, Burke W. Women's interest in genetic testing for breast cancer susceptibility may be based on unrealistic expectations. Am J Med Genet. 2001;99(2):99-110.

10. Bleiker EM, Aaronson K, Menko FH, Hahn DE, van Asperen CJ, Rutgers EJ, et al. Genetic counseling for hereditary cancer: a pilot study on experiences of patients and family members. Patient Educ Couns. 1997;32(12):106-16. 
11. Kotsopoulos J, Lubinski J, Lynch HT, Klijn J, Ghadirian P, Neuhausen SL, et al. Age at first birth and the risk of breast cancer in BRCA1 and BRCA2 mutation carriers. Breast Cancer Res Treat. 2007;105(2):221-8.

12. Andrieu N, Goldgar DE, Easton DF, Rookus M, Brohet R, Antoniou AC, et al. Pregnancies, breast-feeding, and breast cancer risk in the International BRCA1/2 Carrier Cohort Study (IBCCS). J Natl Cancer Inst. 2006;98(8):535-44.

13. Jernström H, Loman N, Johannsson OT, Borg A, Olsson $\mathrm{H}$. Impact of teenage oral contraceptive use in a populationbased series of early-onset breast cancer cases who have undergone BRCA mutation testing. Eur J Cancer. 2005;41(15):2312-20.

14. MalufMFM, Mori LJ, Barros ACSD. O impacto psicológico do câncer de mama. Rev Bras Cancerol. 2005;51(2):149-54.

15. Maluf MFM. O luto no câncer de mama. In: Piato S, Piato JRM. Doenças da mama. Rio de Janeiro: Revinter; 2006. p. 235-9.

16. Dorval M, Patenaude AF, Schneider KA, Kieffer SA, Digianni L, Kalkbrenner KJ, et al. Anticipated versus actual emotional reactions to disclosure of results of genetic tests for cancer susceptibility: findings from $\mathrm{p} 53$ and BRCA1 testing programs. J Clin Oncol. 2000;18(10):2135-42.

17. Maluf MFM. O perfil da sexualidade em mulheres com câncer de mama [Dissertação]. São Paulo (SP): Faculdade de Medicina da Universidade de São Paulo; 2008.

18. Bleiker EMA, Hahn DEE, Aaronson NK. Psychosocial issues in cancer genetics. Acta Oncol. 2003;42(4):276-86.
19. Miesfeldt S, Cohn WF, Jones SM, Ropka ME, Weinstein JC. Breast cancer survivors' attitudes about communication of breast cancer risk to their children. Am J Med Genet C Seminars Med Genet. 2003;119(1):45-50.

20. Ganz PA, Gail AG, Petersen L, Kahn B, Bower JE. Breast cancer in younger women: reproductive and late health effects of treatment. J Clin Oncol. 2003;21(22):4184-93.

21. Hartmann L, Sellers TA, Schaid DJ, FrankTS, Soderberg CL, Sitta DL, et al. Efficacy of bilateral prophylactic mastectomy in BRCA 1 and BRCA 2 gene mutation carries. J Natl Cancer Inst. 2001;93(21):1633-7. Comment in: J Natl Cancer Inst. 2001;93(21):1586-7.

22. Metcalfe KA, Lubinski J, Ghadirian P, Lynch H, KimSing C, Friedman E, et al. Predictors of contralateral prophylactic mastectomy in women with a BRCA1 or BRCA2 mutation: the Hereditary Breast Cancer Clinical Study Group. J Clin Oncol. 2008;26(7):1093-7. Epub 2008 Jan 14.

23. Hatcher MB, Fallowfield L, A'Herm R. The psychosocial impact of bilateral prophylactic mastectomy: prospective study using questionnaires and semistructured interviews. BMJ. 2001;322(7278):76.

24. Friedman LC, Kramer RM. Reproductive issues for women with BRCA mutations. J Natl Cancer Inst Monogr. 2005;(34):83-6.

25. Harris M, Winship I, Spriggs M. Controversies and ethical issues in cancer-genetics clinics. Lancet Oncol. 2005;6(5):301-10.

\section{Abstract}

The objective of this study is to provide knowledge about the impact of the confirmation of mutation in the BRCA1 and BRCA2 genes upon the family planning in patients with high risk for breast cancer, through international literature review. The medical literature is plentiful and rich in relation to the genetic aspects associated to breast cancer since the identification of these genes in 1994 and 1995, supplying precious information about the test and its implication in the life of the mutation carrier such as the decision on prophylactic surgical treatments, however without clearly approaching the question of the family planning. In this condition it becomes essential that the studies on the family planning are further developed to let us understand the impact of this premature discovery in the woman's personal life.

Key words: Breast neoplasms; Gene BRCA1; Gene BRCA2, Mastectomy; Familiar planning; Pregnancy 